\section{Uncommonly interesting}

\section{Paul Colinvaux}

Rarity. By K. J. Gaston. Chapman and Hall: 1994. Pp. 205. £17.95 (pbk).

'RARE' is a term usually used by collectors to mean "I have got one and you haven't". Rarity is thus desirable, as reflected in one of its definitions in the Oxford English Dictionary: "thing valued as being rare". Biologists are not immune to this human foible, rejoicing in a rare bird or an unexpected species in the collecting net.

But for Gaston, in what is apparently the first monograph on biological rarity, 'rarity' merely means of low abundance or of small range, or both. The rare are ubiquitous, an inevitable part of any community. This abundance, as it were, of the rare is what makes rare species interesting. Why are certain species rare? Do ecosystems need them? Are they successful as a species? Is rarity a sign of impending extinction?

Frank Preston made a fundamental observation in his paper "The Commonness and Rarity of Species" (Ecology 29, $254 ; 1948$ ) by showing that the distribution of relative abundance is log-normal. This implies underlying randomness. Subsequent attempts to find more subtle patterns of relative abundance have left few traces. Robert MacArthur's "broken stick" model, in which resources of a community are allocated as if by the random breaking of a stick into bits of unequal length, yields distributions of relative abundance that are themselves functions of the log-normal. Joel Cohen's variant of the broken stick theme, the "balls and buckets" model, in which population size is allocated by the random, sequential throwing of coloured balls into an army of buckets, yields a similar echo of the log-normal. No other models have fired the imaginations of ecologists as did the broken stick.

Gaston believes that interesting questions remain to be answered. He offers no new model or theory of rarity, nor is the history of the broken stick and its allies mentioned. Instead he begins a quest for properties of the rare that can be measured.

Definition is a major problem, and Gaston devotes his first chapter to it. $\mathrm{He}$ concludes that we have no alternative but to assign an arbitrary proportion of species present as rare, essentially the $x$ per cent of species that have lowest abundance or smallest range. Five per cent of total abundance, biomass or range usually provides plenty of species in the 'rare' category.

With the rare so defined, Gaston takes a population biologist's approach to measuring both the rare and the properties that might account for their rarity. Obstacles are formidable. The very rare almost cannot be counted, as when Eric Pianka noted that it takes a hundred person-days to find one specimen of a rare lizard. And to measure the area occupied by species with patchy distributions probably needs the use of fractals.

To investigate the causes of rarity by measurement, as the author wishes, without hypotheses of rarity to test, is more difficult still. Measuring arrays of environmental factors becomes uncomfortably reminiscent of older schools of plant-community analysis, where the aim was to explain plant distributions as consequences of physical parameters of environments alone.

Gaston describes several possible causes of rarity: endemism, individuals at range boundaries, vagrancy, the lows of fluctuating populations, restricted dispersal or establishment, as well as the pseudorarity that results from limits to our powers of detection. He dismisses the concept that some species remain rare because of restricted niche opportunities, because in the few examples where many resources have been measured, he is unable to find any correlation between resource and relative abundance.

As one who once tried to introduce Raymond Lindeman's concept of efficiency of energy transfer between trophic levels with an essay called "Why Big Fierce Animals are Rare", I remain convinced that tigers are rarer than sheep, and that I know why. But this monograph is about the rarity that remains after possible effects of food chains, functional niches, vagrants and sampling error are removed. This remainder is massive. Preston demonstrated the powerful influence of random process in bringing it about. Gaston suggests that experimental measures will find better answers. Perhaps. But it would be more fun to be given a new hypothesis of community-building over which we could argue with the passion ecologists once brought to the broken stick.

Paul Colinvaux is in the Smithsonian Tropical Research Institute, PO Box 2072, Balboa, Panama.

Correction
Aline of text mysteriously disappeared from
Michael Jacobs' review of Environmental Politics
and Greener Management International in this
year's New Journals supplement (Nature 371 ,
$458 ; 1994$ ). His full address is the Centre for the
Study of Environmental Change, University of
Lancaster, Lancaster LA1 4YN, UK.
It has also been brought to our attention that
Glaucus atlanticus, the sea slug pictured on
page 456 of the same issue, does not live on the
sea bed, as stated. The organism is in fact an
important inhabitant of the ocean surface film.

\section{Natural selections}

\author{
RayPercival
}

Realism Rescued. By Rome Harré, Jerrold Aronson and Eileen Cornell Way. Open Court/Duckworth: 1994. Pp. 203. \$42.95, £30 (hbk); \$18.95 (pbk).

How do you put both physicists and biologists on their guard? Answer: propound a philosophical theory that ignores Darwin's demolition of essentialism in species and brands any physicist who denies your theory of natural kinds as an anti-realist.

A traditional division in philosophy is between metaphysics (what sorts of things exist) and epistemology (what and how we know). Some think that the core of realism is the metaphysical assumption that there is a world independent of our minds. But this core assumption is sometimes clothed in other assumptions, such as theories of truth, truth-likeness, meaning and knowledge. Scornful of what they see as an unnecessary retreat from a fully clothed realism to the naked postulate of a mind-independent reality, Harré, Aronson and Way present a realism that also embraces truth and truth-likeness, as well as their own conception of scientific method and the structure of the world.

Informing their whole approach is a challenging view of scientific theories. Theories, they argue, are "essentially" models, or families of models, that constitute their "content". The idea that theories are sets of propositions is rejected. Well-constructed theories consist of a descriptive model, which portrays the phenomena, and an explanatory model, which portrays the unobservable substructure that causes the phenomena. Models are not simply dispensable aids to the construction and understanding of theories, as Duhem would have said. They expand a theory's explanatory power and help us to explain how theories can be continuously revised and extended to new phenomena.

Models represent type-hierarchies and type-hierarchies are pyramidal representations of the ordered hierarchy of natural kinds that make up the world. Borrowed from artificial intelligence, a type-hierarchy analysis, the authors say, is more faithful to our natural use of language, including metaphor and analogy. This is the authors' "naturalistic" approach. But defining realism in this way poses several problems.

In the authors' picture of the structure of the world, natural kinds are ordered in a hierarchy. Thus diamonds are a subtype of crystals, crystals are subtypes of molecular combinations, molecules are subtypes of combinations of atoms, atoms are subtypes of combinations of sub- 